Article

\title{
Public Engagement in Climate Communication on China's Weibo: Network Structure and Information Flows
}

\author{
Yixi Yang * and Mark C. J. Stoddart \\ mstoddart@mun.ca (M.C.J.S.) \\ * Corresponding author \\ Submitted: 16 October 2020 | Accepted: 4 February 2021 | Published: 28 April 2021
}

Department of Sociology, Memorial University of Newfoundland, St. John’s, A1B 1T5, Canada; E-Mails: yixiy@mun.ca (Y.Y.),

\begin{abstract}
This article provides an empirical study of public engagement with climate change discourse in China by analysing how Chinese publics participate in the public discussion around two Intergovernmental Panel on Climate Change reports and how individual users interact with state and elite actors on the pre-eminent Chinese microblogging platform Weibo. Using social network analysis methods and a temporal comparison, we examine the structure of climate communication networks, the direction of information flows among multiple types of Weibo users, and the changes in information diffusion patterns between the pre- and post-Paris periods. Our results show there is an increasing yet constrained form of public engagement in climate communication on Weibo alongside China's pro-environmental transition in recent years. We find an expansion of public engagement as shown by individual users' increasing influence in communication networks and the diversification of frames associated with climate change discourse. However, we also find three restrictive interaction tendencies that limit Weibo's potential to facilitate multi-directional communication and open public deliberation of climate change, including the decline of mutually balanced dialogic interactions, the lack of bottom-up information flows, and the reinforcement of homophily tendencies amongst eco-insiders and governmental users. These findings highlight the coexistence of both opportunities and constraints of Weibo being a venue for public engagement with climate communication and as a forum for a new climate politics and citizen participation in China.
\end{abstract}

\section{Keywords}

climate change communication; China; public engagement; social media; social network analysis

\section{Issue}

This article is part of the issue "Is There a New Climate Politics? Emergency, Engagement and Justice" edited by Anna R. Davies (Trinity College Dublin, Ireland), Stephan Hügel (Trinity College Dublin, Ireland) and Vanesa Castán Broto (University of Sheffield, UK).

(C) 2021 by the authors; licensee Cogitatio (Lisbon, Portugal). This article is licensed under a Creative Commons Attribution 4.0 International License (CC BY).

\section{Introduction}

Since its 13th Five-Year-Plan period (2016-2020), China has undergone a pro-environmental transition and a restructuring of its economy for greener growth. Chinacurrently the world's largest emitter of $\mathrm{CO}_{2}$, and seen as a 'laggard' in Copenhagen (Christoff, 2010)-has recently taken a more proactive role in the global climate regime (see Engels, 2018; Roberts, 2011). China pledged at COP21 to peak its emissions by 2030 and announced in 2020 to further strengthen its target to achieve carbon neutrality by 2060 . Domestically, these pledges have translated into a series of rapid climate policies and state-led programs, such as policies and investments to boost renewable energies and the nationwide "Energy Conservation and Emission Reduction" plan (State Council, 2011). Although China's climate responses remain largely insufficient to meet climate targets, these initiatives demonstrate a positive shift in China's environmental orientation. Some observers 
highlight the significant role of the Chinese central government in steering this pro-environmental transition. They attribute China's environmental turnaround to an authoritarian environmentalism model where a non-participatory approach bypasses public ignorance, conflicts of interest, and other factors that slow or hinder climate action (e.g., Beeson, 2018; Chen \& Lees, 2018). However, recent studies have presented a more nuanced image of China's environmental governance. Internal contestations among governmental agencies, local authorities, and interest groups often exhibit a mixture of both liberal and non-inclusive features in China's multi-level climate governance (e.g., Lo, 2015; Schreurs, 2017). Public participation, in its various forms, is increasingly prevalent and effective in the practice of environmental policy processes (see Wu, Ma, Bian, Li, \& Yi, 2020). Instead of relying on a strong state capacity to override contestation, successful environmental outcomes are often a result of coordination among multiple stakeholders (e.g., Huang, Castán Broto, Liu, \& Ma, 2018).

These important nuances in China's environmental governance show us the need to study China's climate governance as a complex and evolving process and to direct more attention to the interactions among state and non-state actors across different settings. In this study, we explore how such interactions among state, elite, and individual actors unfold in the climate change communication field.

Climate communication helps construct public imaginaries and promotes civic participation around climate change. It is an important arena in which climate change discourse is produced, reproduced, and transformed (Carvalho, 2010; Carvalho, van Wessel, \& Maeseele, 2017). A proliferating body of literature discusses both the positive and negative roles of social media for online discursive interaction and offline action around climate change. However, despite the significance of China's actions (or inaction) in the global decarbonisation process and the increasing penetration of social media in Chinese society, little is known about the way in which climate change is communicated on Chinese social media and the degree to which these channels can be leveraged for public engagement in climate politics. This study looks into how climate communication is carried out on Weibo, a premier social media platform and an important space for public expressions in China. By analysing the structure of communication networks and the direction of information flows in public discussions about the Intergovernmental Panel on Climate Change (IPCC) Fifth IPCC Assessment Report (AR5; IPCC, 2014) and Special Reports on Global Warming of 1.5 ㄷ (SR15; IPCC, 2018), this study sheds light on the often black-boxed interaction processes among state, elite, and individual actors in building public discourse around climate change. Thus we contribute to a better understanding of both the potential and limitations of the Weibosphere for public engagement in China's new climate politics.

\section{Literature Review}

Public engagement with climate change is a multifaceted notion that comprises cognitive, affective, and behavioural dimensions (Lorenzoni, Nicholson-Cole, \& Whitmarsh, 2007). Climate communication plays an important role in many of these facets. Communication helps to create discursive conditions for public engagement as it shapes people's perceptions of and attitudes towards climate change. Discursive interactions in climate communication also provide important venues for the construction of people's political subjectivity in acting on climate change (Carvalho, 2010; Carvalho et al., 2017). A core tenet of public engagement is the promotion of two-way information exchange that enable multiperspective inputs and mutual-learning (Rowe \& Frewer, 2005). Such multi-directional interactions are particularly important in addressing climate change. Being a complex issue situated at the intersections between ecological, economic, political, and social systems, its causes and impacts involve an extraordinarily diverse array of stakeholders. Climate mitigation and adaptation demand coordination between various motivations for (and barriers to) making changes (Baber \& Bartlett, 2005). In light of this, a crucial objective of climate communication is to provide a public space in which actors can present, deliberate, and negotiate their diverse and sometimes contested interests around climate change (Stevenson \& Dryzek, 2014).

A rich body of literature discusses how social media bring in opportunities for-and also challenges to-such multi-directional interactions in disseminating knowledge, shaping public perceptions, coordinating public engagement, and mobilizing political participation around climate change (e.g., O'Neill \& Boykoff, 2012; Pearce, Brown, Nerlich, \& Koteyko, 2015; Segerberg \& Bennett, 2011). However, this body of literature has a noticeable geographical bias as it is largely based on developed Western societies, particularly the Twittersphere (Pearce, Niederer, Özkula, \& Sánchez Querubín, 2019). In the Twitter context, climate communication has been studied from various perspectives, including user-centred research on information exchange, content-based research on themes and sentiments, and reflexive discussions about its technological, social, and political potentials (for a review, see Pearce et al., 2019; Schäfer, 2012). There is, as yet, only a handful of studies looking into how climate communication plays out on China's Weibo (e.g., Liu \& Zhao, 2017; Riley, Wang, Wang, \& Feng, 2016).

Although few Weibo studies are specified in climate communication, research on Weibo's role in civic communication is proliferating. As an important alternative space for public discourse in China, Weibo provides a conduit for presenting voices that were once absent from China's state-operated mass media system allowing them to be debated in public discussion. Even though this process is not free from political, market, or 
algorithm interference, it still introduces positive dynamics into state-society interaction in China (Gu, 2014; Lewis, 2013; Sullivan, 2013; Wang \& Shi, 2018; Zhang \& Lin, 2014). In the environmental field, many studies focus on civil society organizations to investigate how Weibo is leveraged to raise public environmental awareness, facilitate environmental advocacy, and mobilise (non-confrontational) civic action (e.g., Huang, Gui, \& Sun, 2015; Zhang \& Skoric, 2020). Researchers also note the positive translation of online public opinion to environmental policies. A good example is the public debate over air pollution: ignited and escalated on Weibo, this nationwide debate made air pollution a highly visible issue on China's political agenda and eventually led to factory relocation and industrial reform (see Fedorenko \& Sun, 2016). In this light, Weibo is often discussed as an enabling space for the environmental movement and a green public sphere (Liu, 2011; Sima, 2011; Yang, 2009) in China.

However, consistent with critiques of the rigidity of the Habermasian public sphere (e.g., Fraser, 1990), some scholars question whether the public sphere notion fits the complicated and dynamic reality of civic communication in China, where the boundary between state and society is often blurred (Huang, 1993). While many researchers cite censorship as the main reason to question Weibo's political potential, we caution that the interaction between the state and the public on Weibo is more complex than a simple oppression-empowerment dichotomy. The situation on the ground varies across different fields and different levels of political sensitivity. King, Pan, and Roberts (2013) showed that censorship is only limited to curtailing mobilisation of subversive collective action. Rauchfleisch and Schäfer (2015) also found multiple public spheres exit on Weibo and the one associated with environmental issues features a high degree of open criticism and has large-scale participation. In relation to the broader environmental governance, there is also a nuanced body of literature showing complex interplays between the central authority and local agencies (e.g., Lo, 2015), and between state actors and civil society (e.g., Wu, Chang, Yilihamu, \& Zhou, 2017). Van Rooij, Stern, and Fürst (2016) observed that a host of new environmental actors has risen and diversified China's environmental regulatory landscape. Relatedly, scholars have also noted the increasing use of deliberative measures in China's environmental policy processes (Mol \& Carter, 2006; Zhang, $\mathrm{He}, \mathrm{Mol}, \&$ Zhu, 2013). These nuances resonate with what He and Warren (2011) called the deliberative turn in China's political development, where public feedback and participation are increasingly incorporated into governance practice.

These important nuances in China's environmental politics show the need to move beyond a binary view and to direct more research attention toward the interaction process among state, elite, and individual actors. This article explores such interaction processes in the important yet under-researched field of climate communication in China.

We focus on Weibo-mediated public discussions around the IPCC AR5 and SR15 reports. As significant milestones and structuring forces in the development of the international climate regime, IPCC reports are important drivers of media visibility and public debate over climate change (Broadbent et al., 2016). These documents are also important objects in the 'sciencepolicy interface' of the global climate regime because they work to produce the consensus position on climate science and shape climate policy development (Howe, 2014). In the Twitter context, previous studies have examined the communication of IPCC reports on several aspects, including the dominant frames ( $O^{\prime}$ Neill, Williams, Kurz, Wiersma, \& Boykoff, 2015), topics and communities (Pearce, Holmberg, Hellsten, \& Nerlich, 2014), the divergence and interaction between different communities (Holmberg \& Hellsten, 2016), and scientific knowledge translation among stakeholders (Yagodin, Tegelberg, Medeiros, \& Russell, 2016). Newman (2016) studied the spreading of IPCC AR5 on Twitter and found non-elite actors attracted the most attention in public discussions. His study suggested opportunities on Twitter for non-traditional voices to reach large audiences. By contrast, in the Weibo context, Liu and Zhao's study (2017) on the public discussion around the Paris Summit presented a rather bleak picture for public engagement on Weibo. Based on the number of reposts, they argued climate communication on Weibo is dominated by institutional actors, particularly state-owned media and government agencies. However, we argue that climate communication on Weibo is more nuanced than this image of institutional actors' domination. User influence on social media is a multifaceted notion that may not be sufficiently captured by a single indicator such as repost quantity. In this study, we extend previous research findings by investigating user influence from a relational perspective.

Using social network analysis (SNA) methods, we study public engagement in climate communication on Weibo by focusing on information flows and interaction processes among different types of users. Specifically, we ask the following questions: Who participates in the spreading of the AR5 and the SR15 reports on Weibo? To what extent does information flow in a top-down or bottom-up manner? What factors contribute to users' tendencies to participate in the AR5 and SR15 public discussions? We also include a temporal dimension in our analysis to compare the climate communication networks between the AR5 and SR15 periods. Since these two reports were respectively published before and after the pivot in China's environmental orientation, comparing these two periods can shed light on how public engagement has developed alongside China's pro-environmental transition. By offering an empirical assessment of the interaction structure between state, elite, and individual actors, this study contributes to the 
literature of climate communication and public engagement in China's new eco-politics.

\section{Methodology}

We collected publicly accessible Weibo posts containing the keyword 'IPCC报告' (IPCC reports) within 16 months of each report's release (2013 September-2015 January for AR5 and 2018 October-2020 February for SR15). We only focused on original user-generated posts (AR5 $n=1709$, SR15 $n=2505$ ). Figure 1 illustrates the distributions of these posts over weeks. For both reports, public attention was mostly concentrated within a short time immediately after their release. Nevertheless, both reports were discussed persistently over the 16-month timespan and re-attracted public attention with the subsequent publication of related documents.

We used SNA to examine user interactions in public discussions on Weibo. SNA is a family of methods that draw on network and graph theory to investigate social structures. Unlike standard statistical techniques that reduce the social world to aggregates of discrete individuals and examine social behaviours as a function of individuals' attributes, SNA treats actors as 'agentsin-relation' and considers the effects of both individuals' attributes and the relational structure in which they are embedded (Crossley, 2011). Such a relational perspective is particularly useful for our study since information on social media is generated by users (agents) and travels through their online connections (relation).

We extracted all usernames involved in reposting relations and collected their publicly accessible user profile data. There were 316 such users in the AR5 period and 701 in the SR15 period. While these users only represent a very small fraction of the vast Weibosphere, they are nevertheless a meaningful sample for our relationfocused analysis because our primary interest is on users' interaction patterns rather than users per se. Based on users' reposting relationships, we constructed directed and valued networks (as shown in Figure 2 ) to depict the structure of information dissemination, with nodes representing users, directed edges showing the directions of information flows, and edge values indicating the frequencies of reposting relationships.

Our examination consisted of two levels of analysis: We first descriptively analysed user demographics, the content of top posts, and network-level structures to provide an overview of public discussions. We then examined the structure of communication networks using exponential random graph models (Robins, Pattison, Kalish, \& Lusher, 2007). As a statistical tool designed to tackle network data, exponential random graph models allows us to model the probability of relationships in networks as a function of both the individuals' social attributes and the network's structural properties. This helps us examine the structure of information flows between different types of users and identify the factors that affect their likelihood of spreading climate messages on Weibo.

Specifically, we tested three groups of factors. The first two groups address the notion of elite-ness in climate communication. We used multiple factors in our models to represent its different conceptualizations. We distinguished three types of 'elite' users based on their digital social statuses (users were considered high digital social status if their follower sizes are above the median of all sample users in the respective periods), interests in climate science or environmentalism (users were considered as science-affiliated or environmental concerned if their Weibo profiles contain related keywords), and account types (as indicated in Weibo's official verification system). The third group of factors explore two network structural effects that have particular implications for public engagement in climate communication.

To test these factors, we built three sets of exponential random graph models with three groups of
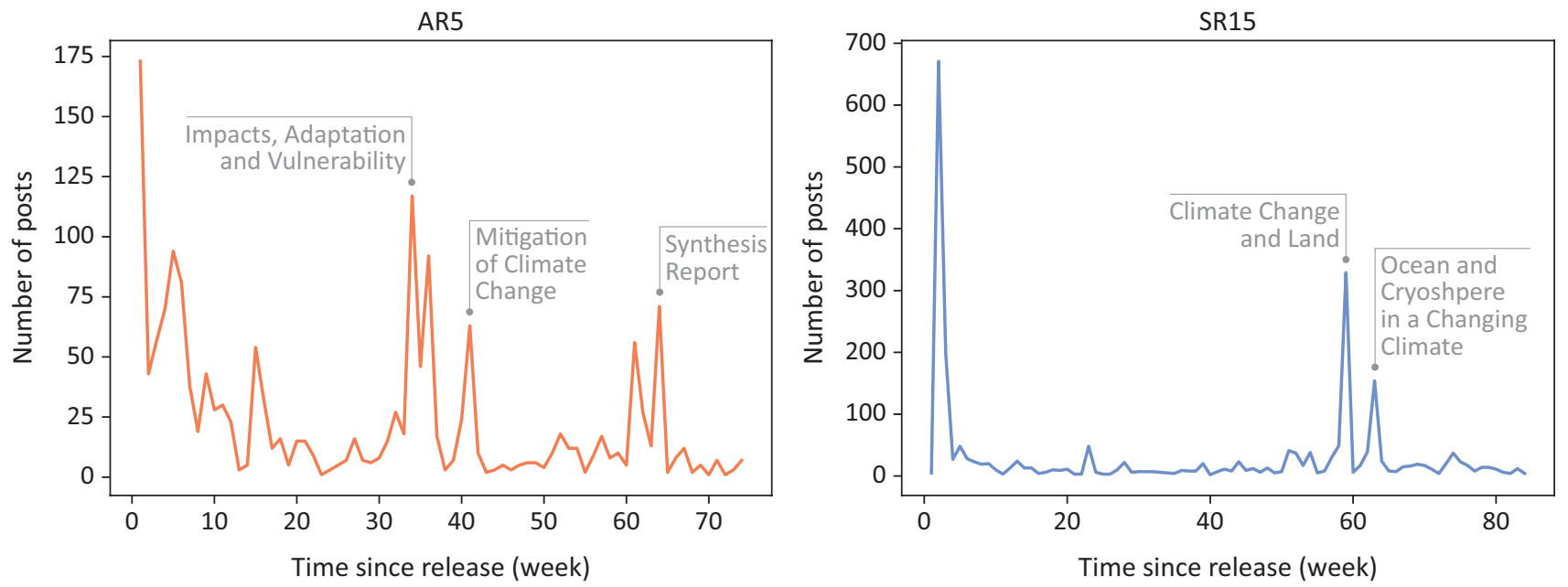

Figure 1. IPCC-related Weibo posts distribution by week since release. Notes: AR5: 27 September 2013 to 30 January 2015 ; SR15: 8 October 2018 to 10 February 2020. 


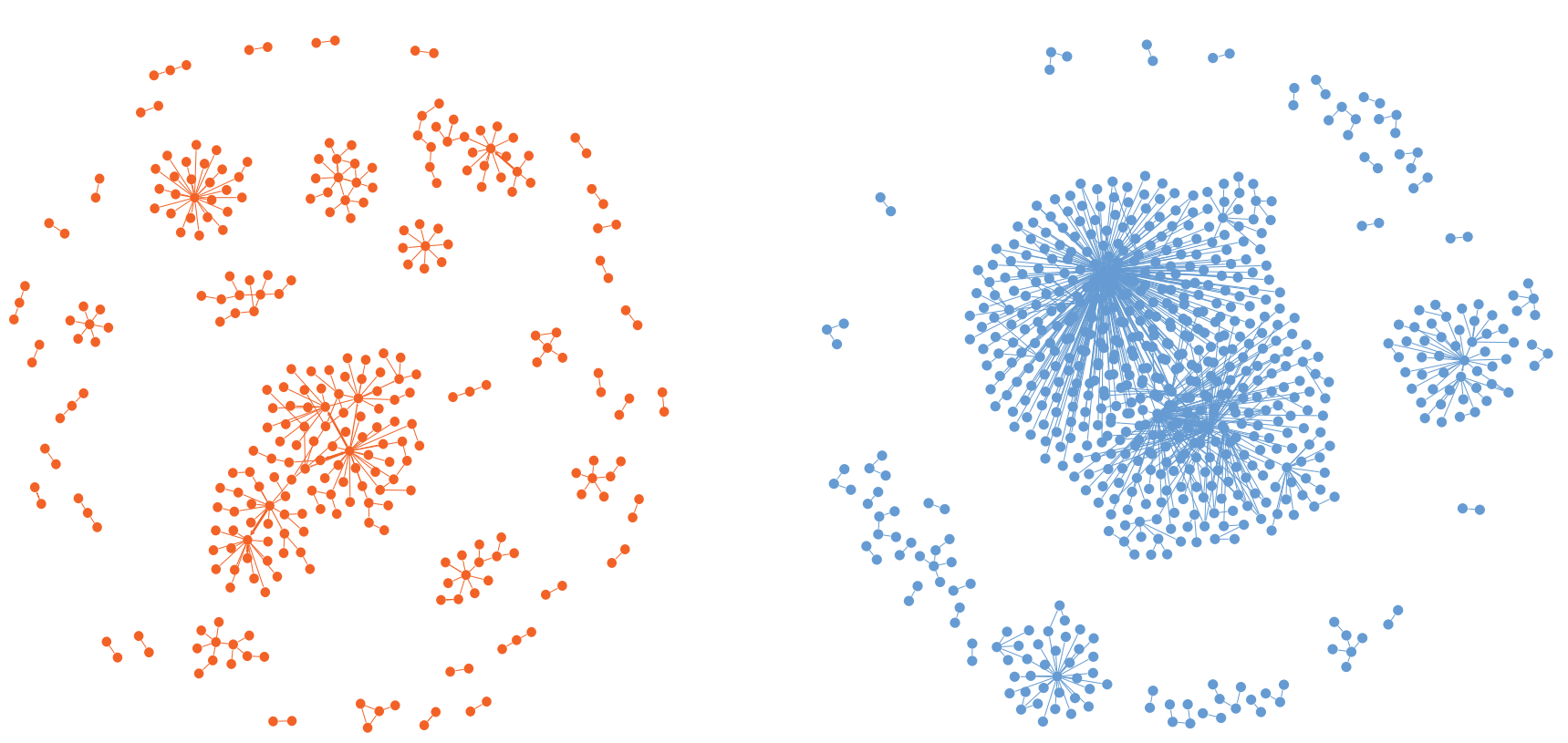

Figure 2. Overview of AR5 network (left) and SR15 network (right), in ForceAtlas2 layout (Jacomy, Venturini, Heymann, \& Bastian, 2014).

hypotheses. The first group of hypotheses examines individuals' attributes. Since a higher status indicates a larger potential audience group on Weibo, we expected a positive effect of a larger follower size on both sending out and receiving climate messages: $\mathrm{H} 1$ users with a large number of followers are more likely to (a) be reposted and (b) repost others. We then tested the effect of being eco-insiders on users' reposting behaviour. Previous studies found internet use promotes citizen participation mainly among those who already have a high interest in or knowledge of relevant issues (see e.g., Min, 2010). We expected a similar positive effect in climate communication so that science-affiliated and environmentally concerned users would be more active than laypeople in obtaining and spreading climate messages: $\mathrm{H} 2$ scienceaffiliated users are more likely to be (a) information senders and (b) information receivers; H3 environmentally concerned users are more likely to be (a) information senders and (b) information receivers.

The second group of hypotheses examines the direction of information flows between individual users and four types of organizational users. Since China's climate responses are often seen as featuring a top-down character, we expected the same mechanism to be mirrored in the communication area so the AR5 and SR15 information would flow from organizational users to individual users: $\mathrm{H} 4$ organizational users, including (a) government, (b) media, (c) business, (d) education, and (e) civil society organizations, are more likely to be information providers for individual users. We also tested whether there is a bottom-up information diffusion pattern: $\mathrm{H} 5$ individual users are more likely to provide information for organizational users, including (a) government, (b) media, (c) business, (d) education, and (e) civil society organizations.
The third group of hypotheses explores two types of network effects. The first is a pair-wise propensity: H6 users tend to form mutually balanced communication relationships by reposting those who have reposted themselves. This mutually balanced form of interaction is important to foster mutual-learning in climate communication. The second network influence is the homophily effect. Homophily describes people's tendency to interact mostly with those who are similar to themselves (McPherson, Smith-Lovin, \& Cook, 2001). This effect has particular relevance in climate communication as it may limit individuals to selective information sources, thus creating echo-chambers which lead to opinion segregation and polarization (see, e.g., Jang \& Hart, 2015). Previous studies revealed that strong homophily exists between climate activist and sceptic groups on Twitter and that this escalates partisan polarization over climate policies, as illustrated in U.S.-oriented research (Carmichael, Brulle, \& Huxster, 2017; Williams, McMurray, Kurz, \& Lambert, 2015). Within the Chinese context, our primary interest was the potential cleavage between the state/elite actors and the general public, so we tested whether a homophily effect exists among eco-insiders and various institutional users: $\mathrm{H} 7$ there is a statistically significant homophily effect amongst eco-insiders (i.e., environmentally concerned and science-affiliated users) and $\mathrm{H} 8$ there is a statistically significant homophily effect amongst organizational users, including those from (a) government, (b) media, (c) business, (d) education, and (e) civil society organizations.

Since our primary interest in this part of the analysis is the structure of information flows rather than the strength of users' relationships, we dichotomized the communication networks based on the presence (1) or 
absence (0) of the reposting relationship between user pairs. Self-loops were also excluded as reposting oneself has little meaning for information diffusion. Models were estimated using the R package 'ergm' (Hunter, Handcock, Butts, Goodreau, \& Morris, 2008).

\section{Results}

\subsection{Expansion of Public Engagement: Scale, Participants, and Network Overview}

From the AR5 to the SR15 period, more people participated in public discussion and actively engaged in interactions with others, as well as more diverse frames associated with climate change on Weibo. We saw increases in the average numbers of reposts (from 12.54 in AR5 to 18.61 in SR15), comments (5.46 to 16.93 ), and likes (4.44 to 26.91). The portion of non-monologic posts (i.e., those with at least one reposting) also increased from $16.96 \%$ in AR5 to $26.63 \%$ in SR15. We also examined the content of the top $1 \%$ most widely circulated posts in each period (AR5 $n=17, \operatorname{SR} 15 n=25$ ). Figure 3 shows the themes which emerged from these top posts. We found early discussions focused on describing and understanding climate change, including news about the release of AR5, the projected climate scenarios, global impacts, infographics, and debates over settled versus uncertain science. This is consistent with Liu and Zhao's (2017) study, which found that Weibo discussions during the Paris Summit period were primarily about raising public awareness, and climate change was mostly presented as a global threat with little relevance to China's national context. However, we saw new developments in the SR15 period. Themes in SR15 discussions became more specific, argumentative, and domestically oriented, covering issues such as the impact on local environments and livelihoods, the urgency of mitigation and adapta- tion action, low-carbon development for national interests, and debate over developed countries' historical carbon debts.

Table 1 compares the network-level descriptive statistics between AR5 and SR15, which shows more detailed changes to communication networks. As indicated by the larger numbers of nodes, edges, diameter, and average path length, the SR15 network had more participants, more reposting relations, and longer information diffusion chains than the AR5 network. However, three vital changes can be observed beneath this overall expansion pattern. First, the intensity of interactions decreased from the AR5 to SR15 period as the network density dropped from $0.31 \%$ to $0.14 \%$. Second, the contradiction between the increased average degree and the decreased average weighted degree indicates that while individual users may interact with more people on average, they were less likely to interact recurrently or maintain their relationships over time. Third, as shown by the decrease in modularity, the SR15 network had fewer closely-knit clusters and presented a flatter structure than the AR5 network. Together, these network-level changes show that expansion of the network's scale did not bring a proportionate growth in interaction intensity. While the communication networks expanded from the AR5 to SR15 periods, interactions on networks became less dense, less recursive, and less clustered.

Another important trend identified by the networklevel comparison is the popularization of climate communication on Weibo. The shares of eco-insiders, users located in China's wealthy developed areas, and those with higher online social statuses dropped significantly from the AR5 to SR15 period. Conversely, there was increased engagement by users from the lay public, underdeveloped regions, and those with lower online social statuses. The popularization trend is also reflected by the rising influence of individual users. We consider
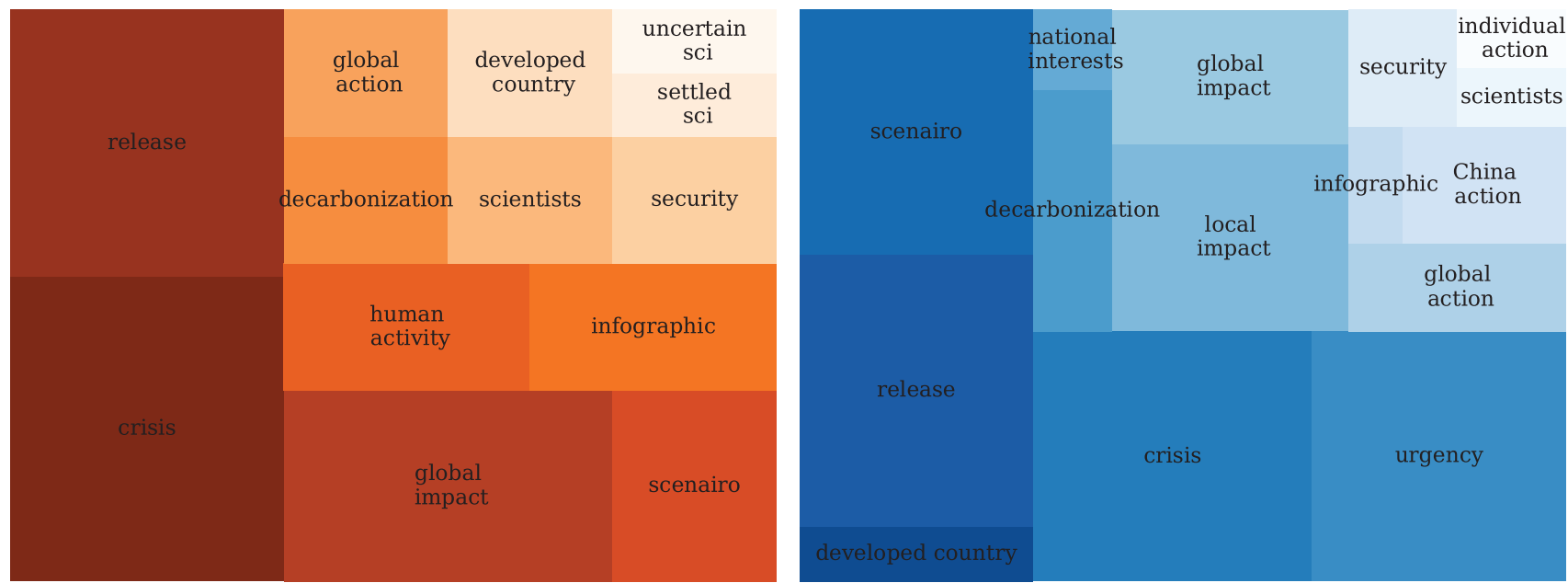

Figure 3. Content themes in the top $1 \%$ most circulated posts in the AR5 period (left) and the SR15 period (right). Notes: A larger square size indicates a higher theme frequency. A darker colour indicates a larger total repost number. A post may contain multiple themes. 
Table 1. Network-level descriptive statistics of the AR5 and SR15 communication networks.

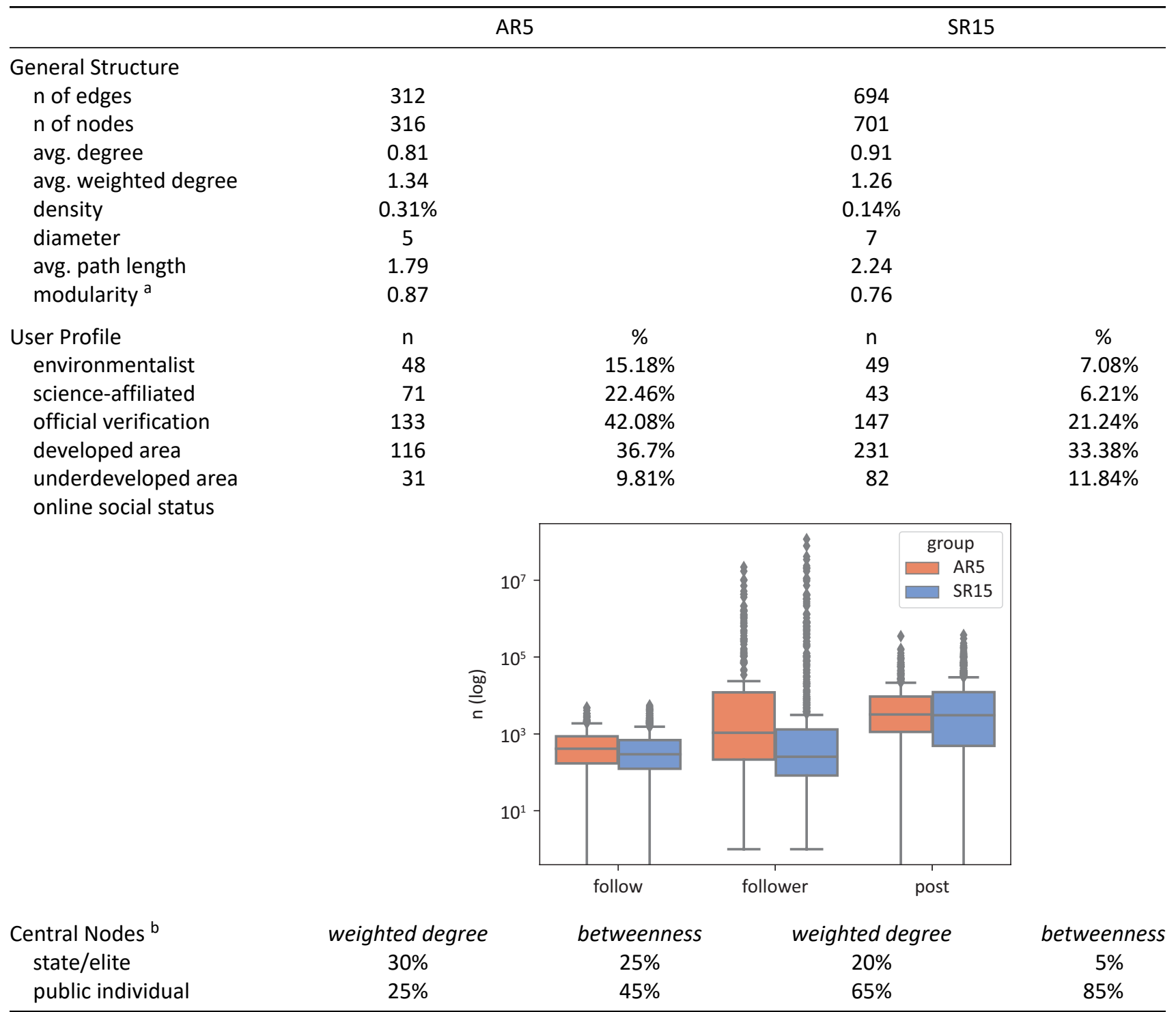

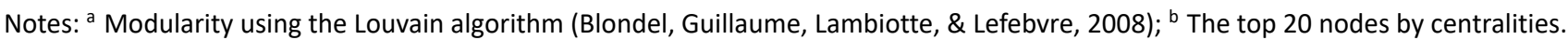

users as influential if they reached a large audience (measured by weighted degree centrality) or bridged information flows between many others (measured by betweenness centrality). Focusing on the top 20 nodes with the highest weighted degree and betweenness centralities, we found more individual users became influential in the SR15 period whereas the share of elite users (e.g., governmental organizations, state-run media, people with official backgrounds) in these central positions dropped significantly over time. Overall, we saw that more individuals from the general public participated in information diffusion and had more opportunities to reach or bridge large audiences in the SR15 network.

\subsection{Limitations to Public Engagement: The Direction of Information Flows}

While the analysis above shows a general expansion of public engagement, a more nuanced picture emerged when we used exponential random graph models to examine interaction processes and information flows between state, elite, and individual users. The modelling results are provided in Table 2 . All models successfully converged and fitted the data well (see the Supplementary File for goodness-of-fit and convergence statistics).

In Model 1, we examined the interaction pattern of three types of elite users, including those with high online social status $(\mathrm{H} 1)$ and those involved in climate science $(\mathrm{H} 2)$ or environmentalism (H3). We found different types of elite users played different roles in information diffusion. First, in both AR5 and SR15 networks, those with a large number of followers were always more likely to send information to, and less likely to receive information from, users with a small number of followers. Second, eco-insider's roles changed over time: Scienceaffiliated users, who tended to be active in both sending and receiving information in the AR5 period, were less active in receiving information in the SR15 period. 
Table 2. Exponential random graph models results of the AR5 and SR15 communication networks.

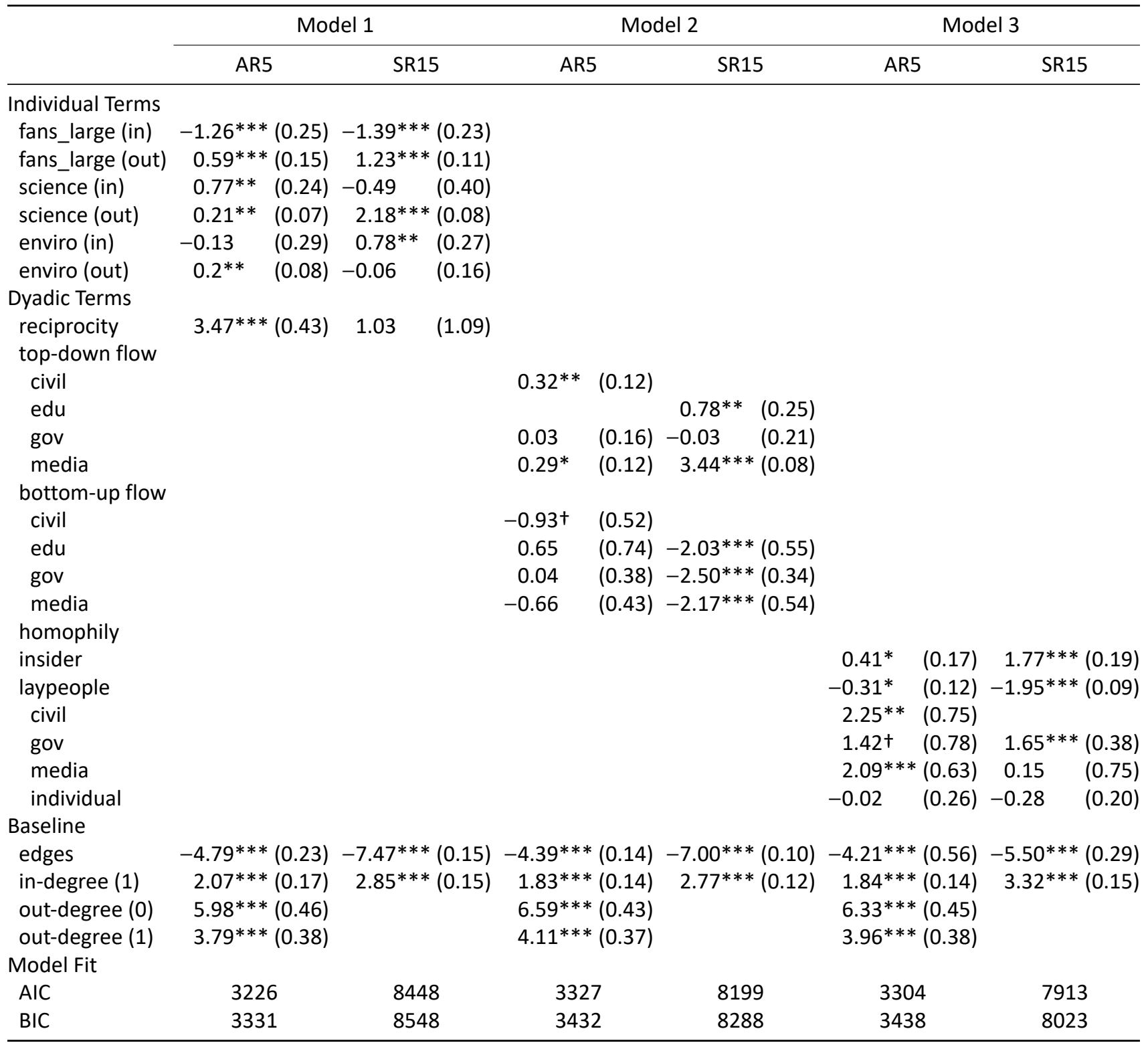

Notes: $+p<0.10 ;^{*} p<0.05 ;^{* *} p<0.01{ }^{* * *} p<0.00$. There were not enough observations of interactions between individual users with the civil society organization group in the SR15 period and the education group in AR5, so their corresponding dyadic terms were dropped in Model 2 and Model 3. Two out-degree controlling terms were added in AR5 models to better fit the data and improve model convergence.

By contrast, while environmentally concerned users tended to be information providers in the AR5 period, they took on more of an audience role in the SR15 period as they became more active in receiving information.

In Model 2, we examined the direction of information flows between organizational users and individual users ( $\mathrm{H} 4$ and $\mathrm{H} 5$ ). We found the diffusion of climate change information on Weibo tended to follow a topdown pattern. As the second block of Table 2 shows, while individual users tended to receive information from civil society organizations in the AR5 period, educational organizations in the SR15 periods, and media organizations in both periods, none of the organization types tended to obtain information from individual users.
In the SR15 network, there were even fewer bottom-up flows from individual users to education, governmental, or media users than one would expect by chance. Overall, we found the top-down pattern of information diffusion was reinforced over time and individual accounts became less likely to be reposted by organizational accounts in climate communication on Weibo. However, this top-down trajectory shows a divergence from Liu and Zhao's previous study (2017), which found that governmental and media users dominated climate communication on Weibo. Our network analysis shows governmental users were not influential information providers for individual users. Instead, only the media users (including mainstream, private, and independent types) played 
a significant role in spreading information to individual users in climate communication on Weibo.

Model 3 tests two network effects. We found the reciprocity effect (H6) was statistically significant only in the AR5 period. The decrease of mutually balanced relations signals a recent decline in interactive conversations in climate communication on Weibo. This may reflect a broader shift of interaction patterns on Weibo towards spreading messages rather than promoting dialogue and opinion exchange. When testing homophily effects, we found eco-insiders (H7) tended to communicate in more closed circles amongst themselves in both periods, whereas users from the general public were more likely to jump out of their circle and obtain information from eco-insiders. We saw a low risk of information cleavage for most organizational types except for governmental users (H8). While there was a homophily tendency within civil society and media organizations in the AR5 period, it was no longer statistically significant in the SR15 period. However, governmental users' homophily tendency was reinforced over time. Since closed communication circles often lead to information cleavage, reinforce people's existing opinions, and exacerbate divergences between groups, the homophily tendencies amongst eco-insiders and governmental users may obstruct them from participating in meaningful public deliberation on Weibo. Furthermore, we noted a hierarchical pattern among governmental users. Figure 4 shows an example from the SR15 network. Within this governmental users' cluster, information flows hierarchically from the Ministry of Ecology and Environment to provincial- and lower-level local environmental protection bureaus, then to subsidiary public organizations and non-state actors. This hierarchical chain provides an example of how a top-down form of environmentalism manifests itself in the communication domain.

\section{Discussion}

Our findings show both opportunities and limitations for climate communication on Weibo alongside China's pro-environmental transition in recent years. From the AR5 to SR15 period, there was a general expansion of public engagement and popularization trends in climate communication on Weibo, as shown by the increased number of participants, diversified climate change frames, and increased influence of individual users in bridging information flows. We examined users' dominance from a relational perspective and found that non-elite individual users became more influential in climate information diffusion on Weibo. Our exponential random graph models results provide more nuances to the general popularization trend. Firstly, we found information flows in climate communication on Weibo largely followed a top-down pattern. Media accounts were the most prominent information source for individuals, whereas the governmental users' role to individual users was not significant. Secondly, among the

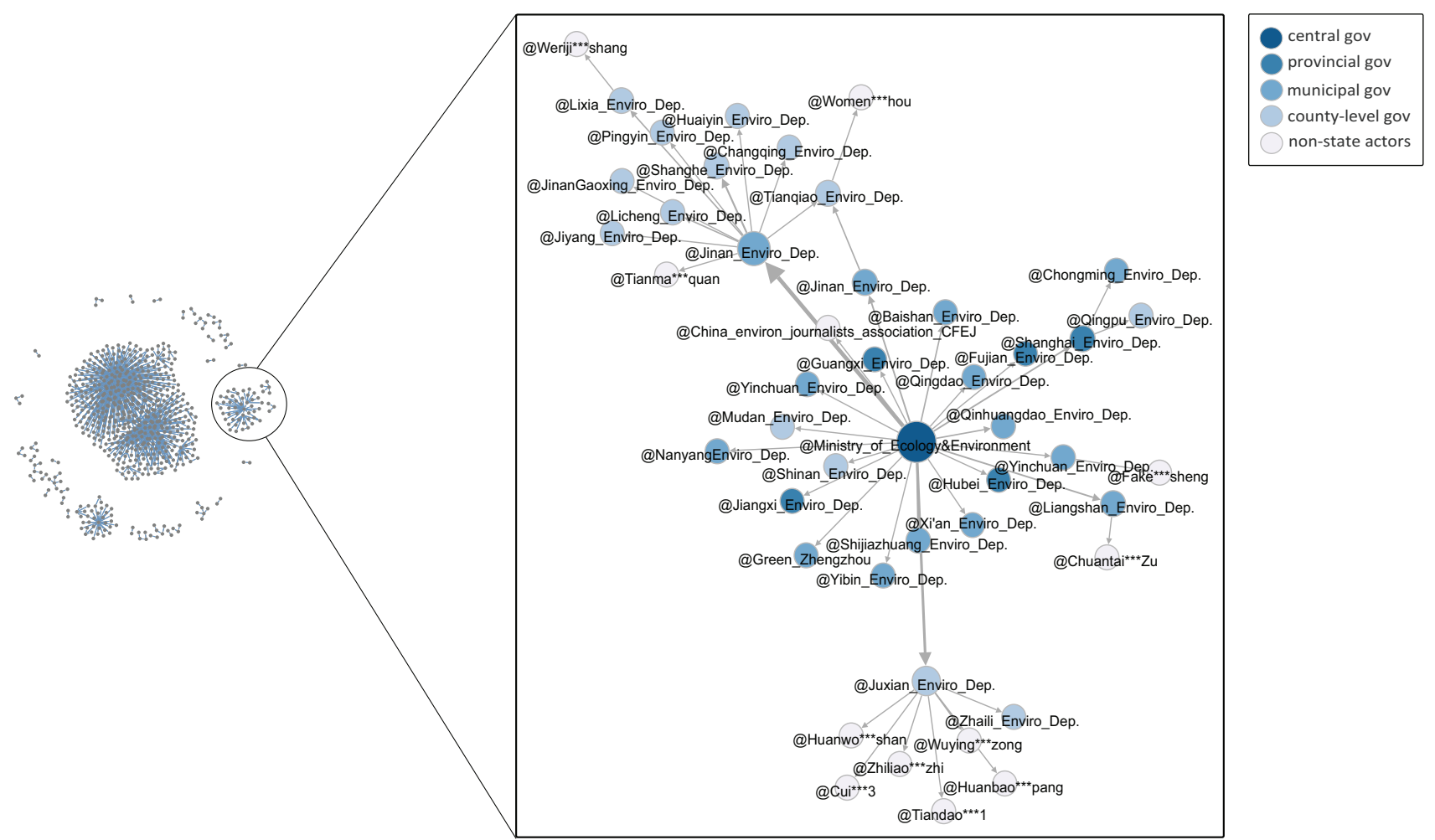

Figure 4. A hierarchic governmental user cluster in the SR15 network. Notes: Left: the whole SR15 network. Right: a governmental user cluster. Node sizes indicate weighted degrees; node colours indicate hierarchic levels; edge arrows show the directions of information flow. Non-state actors' usernames have been anonymized to protect privacy. 
three types of elite users studied in our models, only the environmental user group showed a high probability of obtaining information from the general public users. Those with more followers and those affiliated with climate science tended to play the role of information sources in climate communication. We also found several trends that limit Weibo's potential for facilitating multi-directional public engagement in climate communication, including the decrease of interaction intensity, the decline of mutually-balanced dialogues, the reinforcement of top-down diffusion pattern, and persistent homophily tendencies amongst eco-insiders and governmental users.

These findings present a mixed picture of the interaction process among state, elite, and individual actors, which helps us to reconsider Weibo's role in climate communication. Social media's potential for public engagement and political participation derives from the interactivity and connectivity embedded in their techno-social infrastructure. While interactivity enables people to be engaged in multi-directional opinion exchanges and public deliberation, connectivity generates 'mediated public connection' (Couldry, Livingstone, \& Markham, 2007) that allows fragmented individual conversations, experiences, and beliefs to be consolidated into public discourses and collective values. Despite the theoretical potential, the degree to which interactivity and connectivity translate into opportunities for public engagement varies across different contexts. First, we have to ask who the public are: The actors that constitute 'the public' in climate politics are not a homogenous or unified whole (Whitmarsh, O'Neill, \& Lorenzoni, 2013). Instead, there are a nexus of multiple publics (Fraser, 1990) who interpret climate change, each with their own vested interests, perceptions, and 'cultural competencies' (Burgess, Harrison, \& Maiteny, 1991). Second, complexity also arises from the structure of interactions. While some interactions create bridging and bonding opportunities that translate connectivity into social capital, other interactions produce restrictive structures. Therefore, in our analysis, we first distinguished Weibo users by their types, online social status, and their interest or involvement in climate science and eco-protection. We then examined the structure of their interactions and the direction of information flows in this structure to discuss Weibo's potential to facilitate open and multidirectional communication. Our empirical results presented the process and complexity in Weibo interaction from a relational network perspective, thus contributing to the ongoing debate about both the potential for and limitations of leveraging social media for public engagement with climate change.

Our analyses show both enabling opportunities and constraining conditions on Weibo. While we do find signs of Weibo's democratizing potential as a green public sphere (Yang, 2009), we also see how greater participation may not translate into political efficacy in terms of the ability of citizen voices to reach elite state actors.
Such a coexistence between the expansion of public engagement and the top-down information diffusion pattern in climate communication resonates with the notion that the Chinese political sphere is undergoing a shift, becoming more 'responsive' (Mertha, 2009), where public participation is increasingly incorporated into environmental governance, but public participation does not challenge the centrality of state elite actors. This mixed image suggests that Weibo does not necessarily lead to a more autonomous or bottom-up climate politics, but neither does it simply maintain official and elite users' dominance in shaping the public discourse of climate change. This two-sided image highlights the limitation of viewing Weibo as a normative Habermasian public sphere in China's eco-politics. China's environmental movement and governance are characterised by an interpenetration between the state and the civil society (Ho \& Edmonds, 2007). Therefore, to better understand China's climate politics, we have to move beyond a dualistic view that rests on a binary opposition between state and civil society, and direct more attention to the processes through which state and civil society interact, as well as their contexts and dynamics.

This study is subjected to several limitations. First, the size of the dataset we examined was limited by our choice to focus on public discussions around IPCC reports rather than climate change in general. Although studying this specific topic allows us to focus on the core conceptions of climate change, these event-triggered discussions cannot fully represent how climate change is discussed in everyday life. Future studies would benefit from a larger dataset that includes more issue- and theme-based public discussions to capture a more comprehensive picture of climate change discourse. Second, we measured users' influence by their degree of centrality in communication networks. While node centralities are important indicators of prominence in network analysis, users' influence in communication is nevertheless a multifaceted concept. Future research will benefit from incorporating other indicators to gauge different aspects of communicative influence. Relatedly, we focused on the process of information diffusion through sharing relationships. There are other important dimensions of communication. Particularly, future studies could focus on the ideational content in climate communication and the quality of deliberation by conducting an in-depth qualitative analysis of public discussions.

\section{Conclusion}

This article provides an empirical study of public engagement with climate change discourse in China by analysing the information flows among state, elite, and individual users in public discussions around two IPCC reports on China's prominent social media platform Weibo. Our results show there is an increasing yet constrained form of public engagement in climate communication on Weibo. We find public engagement expanded alongside 
China's recent pro-environmental transition as individual users became increasingly influential in initiating public discussions and disseminating climate messages in communication networks. Relatedly, we observe a popularization trend of the climate change discourse as shown by the diversification of participants and frames in public discussions. Conversely, we found three restrictive interaction patterns that highlight the limitations of Weibo as a space for a new climate politics in China. First, the decline of mutually balanced dialogic interactions reduces Weibo's potential to facilitate meaningful public deliberation around climate change. Second, the lack of bottom-up information flows indicates a deficit of public feedback and input, which limits Weibo's potential for facilitating genuine multi-directional communication in public engagement. Third, closed communication circles amongst eco-insiders and governmental users may confine them to selective information and opinions, create cleavages between these elite users and the general public, and thus obstruct mutual-learning and open opinion exchange in climate communication.

\section{Acknowledgments}

The authors would like to thank John McLevey, Karen Stanbridge, and Liam Swiss for their input throughout the development of this project. We thank the three anonymous reviewers and the Academic Editors for their valuable comments and suggestions. This project was supported by Memorial University of Newfoundland School of Graduate Studies and an Insight Grant from the Social Sciences and Humanities Research Council of Canada (SSHRC).

\section{Conflict of Interests}

The authors declare no conflict of interests.

\section{Supplementary Material}

Supplementary material for this article is available online in the format provided by the author (unedited).

\section{References}

Baber, W. F., \& Bartlett, R. V. (2005). Deliberative environmental politics: Democracy and ecological rationality. Cambridge, MA: MIT Press Cambridge.

Beeson, M. (2018). Coming to terms with the authoritarian alternative: The implications and motivations of China's environmental policies. Asia \& the Pacific Policy Studies, 5(1), 34-46.

Blondel, V. D., Guillaume, J.-L., Lambiotte, R., \& Lefebvre, E. (2008). Fast unfolding of communities in large networks. Journal of Statistical Mechanics: Theory and Experiment, 2008(10). https://doi.org/10.1088/ 1742-5468/2008/10/p10008

Broadbent, J., Sonnett, J., Botetzagias, I., Carson, M., Car- valho, A., Chien, Y.-J., . . . Haluza-DeLay, R. (2016). Conflicting climate change frames in a global field of media discourse. Socius, 2, 1-17.

Burgess, J., Harrison, C., \& Maiteny, P. (1991). Contested meanings: The consumption of news about nature conservation. Media, Culture \& Society, 13(4), 499-519.

Carmichael, J. T., Brulle, R. J., \& Huxster, J. K. (2017). The great divide: Understanding the role of media and other drivers of the partisan divide in public concern over climate change in the USA, 2001-2014. Climatic Change, 141(4), 599-612.

Carvalho, A. (2010). Media(ted) discourses and climate change: A focus on political subjectivity and (dis)engagement. WIREs Climate Change, 1(2), 172-179.

Carvalho, A., van Wessel, M., \& Maeseele, P. (2017). Communication practices and political engagement with climate change: A research agenda. Environmental Communication, 11(1), 122-135.

Chen, G. C., \& Lees, C. (2018). The New, green, urbanization in China: Between authoritarian environmentalism and decentralization. Chinese Political Science Review, 3(2), 212-231.

Christoff, P. (2010). Cold climate in Copenhagen: China and the United States at COP15. Environmental Politics, 19(4), 637-656.

Couldry, N., Livingstone, S., \& Markham, T. (2007). Connection or disconnection? Tracking the mediated public sphere in everyday life. In R. Butsch (Ed.), Media and public spheres (pp. 28-42). Basingstoke and New York, NY: Springer.

Crossley, N. (2011). Towards relational sociology. New York, NY: Routledge.

Engels, A. (2018). Understanding how China is championing climate change mitigation. Palgrave Communications, 4(1). http://dx.doi.org/10.1057/s41599018-0150-4

Fedorenko, I., \& Sun, Y. (2016). Microblogging-based civic participation on environment in China: A case study of the PM 2.5 campaign. Voluntas, 27(5), 2077-2105.

Fraser, N. (1990). Rethinking the public sphere: A contribution to the critique of actually existing democracy. Social Text, (25/26), 56-80.

Gu, Q. (2014). Sina Weibo: A mutual communication apparatus between the Chinese government and Chinese citizens. China Media Research, 10(2), 72-85.

He, B., \& Warren, M. E. (2011). Authoritarian deliberation: The deliberative turn in Chinese political development. Perspectives on Politics, 9(2), 269-289.

Ho, P., \& Edmonds, R. (Eds.). (2007). China's embedded activism: Opportunities and constraints of a social movement. Abingdon: Routledge.

Holmberg, K., \& Hellsten, I. (2016). Twitter campaigns around the Fifth IPCC Report: Campaign spreading, shared hashtags, and separate Communities. SAGE Open, 6(3). https://doi.org/10.1177/ 2158244016659117 
Howe, J. P. (2014). Behind the curve: Science and the politics of global warming. London: University of Washington Press.

Huang, P., Castán Broto, V., Liu, Y., \& Ma, H. (2018). The governance of urban energy transitions: A comparative study of solar water heating systems in two Chinese cities. Journal of Cleaner Production, 180, 222-231.

Huang, P. C. (1993). "Public sphere"/"civil society" in China? The third realm between state and society. Modern China, 19(2), 216-240.

Huang, R., Gui, Y., \& Sun, X. (2015). Inter-organizational network structure and formation mechanisms in Weibo space: A study of environmental NGOs. Chinese Journal of Sociology, 1(2), 254-278.

Hunter, D. R., Handcock, M. S., Butts, C. T., Goodreau, S. M., \& Morris, M. (2008). ergm: A package to fit, simulate and diagnose exponential-family models for networks. Journal of Statistical Software, 24(3). http:// dx.doi.org/10.18637/jss.v024.i03

Intergovernmental Panel on Climate Change. (2014). Climate change 2014: Synthesis report. Geneva: Intergovernmental Panel on Climate Change.

Intergovernmental Panel on Climate Change. (2018). Global warming of $1.5^{\circ} \mathrm{C}$ : An IPCC special report on the impacts of global warming of $1.5^{\circ} \mathrm{C}$ above preindustrial level and related global greenhouse gas emission pathways, in the context of strengthening the global responses to the threat of climate change, sustainable development, and efforts to eradicate poverty. Geneva: Intergovernmental Panel on Climate Change.

Jacomy, M., Venturini, T., Heymann, S., \& Bastian, M. (2014). ForceAtlas2, a continuous graph layout algorithm for handy network visualization designed for the Gephi software. Plos One, 9(6). https://doi.org/ 10.1371/journal.pone.0098679

Jang, S. M., \& Hart, P. S. (2015). Polarized frames on "climate change" and "global warming" across countries and states: Evidence from Twitter big data. Global Environmental Change, 32, 11-17.

King, G., Pan, J., \& Roberts, M. E. (2013). How censorship in China allows government criticism but silences collective expression. American Political Science Review, 107(2), 326-343.

Lewis, O. A. (2013). Net inclusion: New media's impact on deliberative politics in China. Journal of Contemporary Asia, 43(4), 678-708.

Liu, J. (2011). Picturing a green virtual public space for social change: A study of Internet activism and webbased environmental collective actions in China. Chinese Journal of Communication, 4(2), 137-166.

Liu, J. C., \& Zhao, B. (2017). Who speaks for climate change in China? Evidence from Weibo. Climatic Change, 140(3-4), 413-422.

Lo, K. (2015). How authoritarian is the environmental governance of China? Environmental Science \& Policy, 54, 152-159.
Lorenzoni, I., Nicholson-Cole, S., \& Whitmarsh, L. (2007). Barriers perceived to engaging with climate change among the UK public and their policy implications. Global Environmental Change, 17(3), 445-459.

McPherson, M., Smith-Lovin, L., \& Cook, J. M. (2001). Birds of a feather: Homophily in social networks. Annual Review of Sociology, 27(1), 415-444.

Mertha, A. (2009). "Fragmented authoritarianism 2.0": Political pluralization in the Chinese policy process. The China Quarterly, 200, 995-1012.

Min, S.-J. (2010). From the digital divide to the democratic divide: Internet skills, political interest, and the second-level digital divide in political internet use. Journal of Information Technology \& Politics, 7(1), 22-35.

Mol, A. P. J., \& Carter, N. T. (2006). China's environmental governance in transition. Environmental Politics, 15(2), 149-170.

Newman, T. P. (2016). Tracking the release of IPCC AR5 on Twitter: Users, comments, and sources following the release of the Working Group I Summary for Policymakers. Public Understanding of Science, 26(7), 815-825.

O'Neill, S., \& Boykoff, M. (2012). The role of new media in engaging the public with climate change. In L. Whitmarsh, I. Lorenzoni \& S. O'Neill (Eds.), Engaging the public with climate change: Behaviour change and communication (pp. 259-277). London: Routledge.

O'Neill, S., Williams, H. T. P., Kurz, T., Wiersma, B., \& Boykoff, M. (2015). Dominant frames in legacy and social media coverage of the IPCC Fifth Assessment Report. Nature Climate Change, 5(4), 380-385.

Pearce, W., Brown, B., Nerlich, B., \& Koteyko, N. (2015). Communicating climate change: Conduits, content, and consensus. WIREs Climate Change, 6(6), 613-626.

Pearce, W., Holmberg, K., Hellsten, I., \& Nerlich, B. (2014). Climate change on Twitter: Topics, communities and conversations about the 2013 IPCC Working Group 1 report. Plos One, 9(4). https://doi.org/ ARTNe9478510.1371/journal.pone.0094785

Pearce, W., Niederer, S., Özkula, S. M., \& Sánchez Querubín, N. (2019). The social media life of climate change: Platforms, publics, and future imaginaries. WIREs Climate Change, 10(2). https://doi.org/ 10.1002/wcc.569

Rauchfleisch, A., \& Schäfer, M. S. (2015). Multiple public spheres of Weibo: A typology of forms and potentials of online public spheres in China. Information, Communication \& Society, 18(2), 139-155.

Riley, P., Wang, R., Wang, Y., \& Feng, L. (2016). Global warming: Chinese narratives of the future. Global Media and China, 1(1/2), 12-31.

Roberts, J. T. (2011). Multipolarity and the new world (dis)order: US hegemonic decline and the fragmentation of the global climate regime. Global Environmental Change, 21(3), 776-784.

Robins, G., Pattison, P., Kalish, Y., \& Lusher, D. (2007). 
An introduction to exponential random graph ( $\left.\mathrm{p}^{*}\right)$ models for social networks. Social Networks, 29(2), 173-191.

Rowe, G., \& Frewer, L. J. (2005). A typology of public engagement mechanisms. Science, Technology, \& Human Values, 30(2), 251-290.

Schreurs, M. (2017). Multi-level climate governance in China. Environmental Policy and Governance, 27(2), 163-174.

Segerberg, A., \& Bennett, W. L. (2011). Social media and the organization of collective action: Using Twitter to explore the ecologies of two climate change protests. The Communication Review, 14(3), 197-215.

Sima, Y. (2011). Grassroots environmental activism and the Internet: Constructing a green public sphere in China. Asian Studies Review, 35(4), 477-497.

State Council. (2011). Guo wu yuan guan yu yin fa 'shi er wu' jie neng jian pai Zhong he xing gong zuo fang an de tong zhi [The notice of the State Council on issuing the comprehensive work plan for energy conservation and emission reduction during the 'Twelfth Five-Year Plan' period] (No. 26). Beijing: State Council of the People's Republic of China.

Stevenson, H., \& Dryzek, J. S. (2014). Democratizing global climate governance. Cambridge: Cambridge University Press.

Sullivan, J. (2013). China's Weibo: Is faster different? New Media \& Society, 16(1), 24-37.

Van Rooij, B., Stern, R. E., \& Fürst, K. (2016). The authoritarian logic of regulatory pluralism: Understanding China's new environmental actors. Regulation \& Governance, 10(1), 3-13.

Wang, H., \& Shi, F. (2018). Weibo use and political participation: The mechanism explaining the positive effect of Weibo use on online political participation among college students in contemporary China. Information, Communication \& Society, 21(4), 516-530.

Whitmarsh, L., O’Neill, S., \& Lorenzoni, I. (2013). Public engagement with climate change: What do we know and where do we go from here? International Journal of Media and Cultural Politics, 9(1), 7-25.

Williams, H. T., McMurray, J. R., Kurz, T., \& Lambert, F. H. (2015). Network analysis reveals open forums and echo chambers in social media discussions of climate change. Global Environmental Change, 32, 126-138.

Wu, J., Chang, I. S., Yilihamu, Q., \& Zhou, Y. (2017). Study on the practice of public participation in environmental impact assessment by environmental nongovernmental organizations in China. Renewable and Sustainable Energy Reviews, 74, 186-200.

Wu, L., Ma, T., Bian, Y., Li, S., \& Yi, Z. (2020). Improvement of regional environmental quality: Government environmental governance and public participation. Science of The Total Environment, 717. https://doi.org/ 10.1016/j.scitotenv.2020.137265

Yagodin, D., Tegelberg, M., Medeiros, D., \& Russell, A. (2016). Following the tweets: What happened to the IPCC AR5 Synthesis Report on Twitter? In R. Kunelius, E. Eide, M. Tegelberg, \& D. Yagodin (Eds.), Media and global climate knowledge (pp. 193-211). New York, NY: Palgrave Macmillan.

Yang, G. (2009). The power of the Internet in China: Citizen activism online. New York, NY: Columbia University Press.

Zhang, L., He, G., Mol, A. P. J., \& Zhu, X. (2013). Power politics in the revision of China's Environmental Protection Law. Environmental Politics, 22(6), 1029-1035.

Zhang, N., \& Skoric, M. M. (2020). Getting their voice heard: Chinese environmental NGO's Weibo activity and information sharing. Environmental Communication, 14(6), 844-858.

Zhang, X., \& Lin, W.-Y. (2014). Political participation in an unlikely place: How individuals engage in politics through social networking sites in China. International Journal of Communication, 8(1), 21-42.

\section{About the Authors}

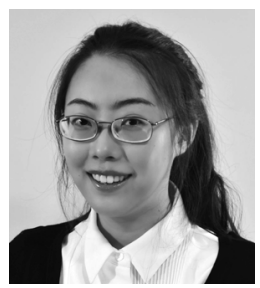

Yixi Yang is a PhD Candidate at the Memorial University of Newfoundland, Canada. Her research interests include climate change communication, environmental sociology, the environmental movement in China, digital sociology, and computational social science. Her current research examines environmental discourses in China's digital media sphere, public participation in climate politics in China, and the role of social networks in shaping public perceptions of climate change.

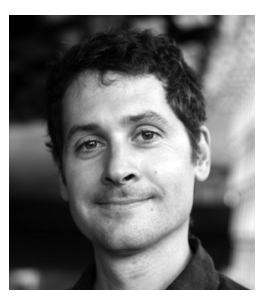

Mark C. J. Stoddart is Professor in the Department of Sociology at Memorial University with research interests in environmental sociology, social movements, and communications and culture. He is the author of the book Industrial Development and Eco-Tourism: Can Oil Extraction and Nature Conservation Co-Exist? (Palgrave). His work appears in a range of international journals, including Global Environmental Change, Energy Research \& Social Science, Organization \& Environment, Environmental Politics, Journal of Sustainable Tourism, Environmental Communication, Mobilities, and Social Movement Studies. 